\title{
Transition of Depressive Symptoms and Anxiety Symptoms According to Parity and Associations of These Symptoms with Feelings for Involvement with Newborn Infants during a 6-Month Postpartum Period
}

\author{
Rumi Ishihara ${ }^{1,2}$, Keiko Nagamine ${ }^{3}$, Yoshie Nishikawa4, Mari Haku5, \\ Hirokazu Uemura6, Yukie Matsuura7, Toshiyuki Yasui ${ }^{7}$ \\ ${ }^{1}$ Midwifery Program, Kagawa Prefectural University of Health Sciences, Kagawa, Japan \\ ${ }^{2}$ Tokushima University Graduate School, Tokushima, Japan \\ ${ }^{3}$ Kansai University of Nursing and Health Sciences, Hyogo, Japan \\ ${ }^{4}$ Tsurugi-Handa Hospital, Tokushima, Japan \\ ${ }^{5}$ Department of Midwifery, Tokushima University Graduate School of Biomedical Sciences, Tokushima, Japan \\ ${ }^{6}$ College of Nursing Art and Science, University of Hyogo, Hyogo, Japan \\ ${ }^{7}$ Department of Reproductive and Menopausal Medicine, Tokushima University Graduate School of Biomedical Sciences, \\ Tokushima, Japan \\ Email: *ishihara@chs.pref.kagawa.jp
}

How to cite this paper: Ishihara, R., Nagamine, K., Nishikawa, Y., Haku, M., Uemura, H., Matsuura, Y. and Yasui, T. (2020) Transition of Depressive Symptoms and Anxiety Symptoms According to Parity and Associations of These Symptoms with Feelings for Involvement with Newborn Infants during a 6-Month Postpartum Period. Open Journal of Obstetrics and Gynecology, 10, 1315-1330.

https://doi.org/10.4236/ojog.2020.1090121

Received: August 17, 2020

Accepted: September 21, 2020

Published: September 24, 2020

\section{Copyright $\odot 2020$ by author(s) and} Scientific Research Publishing Inc. This work is licensed under the Creative Commons Attribution International License (CC BY 4.0).

http://creativecommons.org/licenses/by/4.0/

\begin{abstract}
Background: Depressive symptoms and anxiety symptoms during the postpartum period affect physical health and child rearing and that these effects are important social issues. Objective: The aims of this study were to clarify the differences in the transition of depressive symptoms and anxiety symptoms according to parity during a 6-month postpartum period and to clarify the differences in associations of depressive symptoms and anxiety symptoms with feelings for involvement with newborn infants in primiparous and multiparous postpartum women. Methods: The design of this study was a longitudinal investigation. This study was conducted from February 2017 to July 2018 in Japan. By using self-administered questionnaires that included questions on psychological symptoms in a standard climacteric scale and questions on feelings for involvement with newborn infants, we collected data at 3 days postpartum, 2 weeks postpartum, one month postpartum, 3 months postpartum and 6 months postpartum. Results: Responses to all of the questionnaires were obtained from $121(52.8 \%)$ of 229 women. The score for depressive symptoms in primiparous women was significantly higher than that
\end{abstract}


in multiparous women at 3 days postpartum. Depressive symptoms and anxiety symptoms showed peaks at 2 weeks postpartum in both primiparous women and multiparous women, but depressive symptoms reoccurred from 3 months postpartum to 6 months postpartum in primiparous women and anxiety symptoms reoccurred from one month to 3 months postpartum in multiparous women. Depressive symptoms and anxiety symptoms were associated with negative feelings for involvement with newborn infants and with mother's sleeping time. Conclusion: Changes in depressive symptoms and anxiety symptoms were different in primiparous women and multiparous women during a 6-month postpartum period. In addition, depressive symptoms and anxiety symptoms were associated with negative feelings for involvement with newborn infants and with sleeping time in postpartum women.

\section{Keywords}

Depressive Symptoms, Anxiety Symptoms, Parity, Involvement with Newborn Infants

\section{Introduction}

It has been reported that psychological symptoms such as depressive symptoms and anxiety symptoms during the postpartum period affect physical health and child rearing and that these effects are important social issues in Japan [1] [2] and in the world [3] [4]. Regarding the transition of depressive symptoms in postpartum women, it was shown in a longitudinal study that the proportion of women with depressive symptoms peaked at 2 weeks postpartum and was decreased at 3 months postpartum [5]. Another study conducted for a 6-month postpartum period showed that the proportion of women with depressive symptoms peaked at one month postpartum [6]. On the other hand, a cohort study showed that the proportion of women with anxiety symptoms increased until one month postpartum and was decreased at 4 months postpartum [7]. Changes in ovarian steroid hormones and hypoactivation of the hypothalamic-pituitary-adrenal axis have been suggested to be biological risk factors for postpartum psychological symptoms [8] [9] [10]. Given that ovulation was found at about 6 months after delivery in lactating women and at 45 days after delivery in non-lactating women [11], the changes in psychological symptoms during a 6-month postpartum period need to be clarified in a prospective study.

Regarding the possibility of differences depending on parity, it has been reported that there were no differences in the prevalence of depressive symptoms and anxiety symptoms between primiparous women and multiparous women [7]. However, during a one-month postpartum period, the proportion of women with depressive symptoms was high in primiparous women [6]. In addition, primiparity was shown to be a risk factor for postpartum depression [12] [13]. The results of those studies are controversial. On the other hand, it has been re- 
ported that psychological status of postpartum women was closely associated with positive feelings of postpartum women towards newborn infants such as feelings that taking care of the baby is fun or the baby is cute [14]. However, regarding the association of psychological status of postpartum women with feelings for involvement with newborn infants, a difference between primiparous women and multiparous women has not been clarified.

The aims of this prospective study were to clarify the transition of depressive symptoms and anxiety symptoms during a 6-month postpartum period and to clarify the differences in associations of depressive symptoms and anxiety symptoms with feelings for involvement with newborn infants in primiparous women and multiparous women.

\section{Methods}

This study was conducted from February 2017 to July 2018. The necessary sample size was calculated to be 150 by using permissible errors (5\%), reliability (95\%) and a ratio of a population (50\%), and the appropriate sample size was determined to be 229 considering the probable number of uncollected questionnaire forms for a prospective study. Postpartum women who had given birth through vaginal delivery or Cesarean section were recruited at two birth centers in Japan in which the number of births is approximately 750 per year. The periods of admission for delivery were about 5 days for primiparous women and about 4 days for multiparous women, and breastfeeding alone for the infants was not promoted in either of the hospitals. On the day of delivery and 3 days postpartum, we asked postpartum women to participate in our study and we obtained agreement by signature on a consent form. We distributed five self-administered questionnaires at 3 days postpartum, 2 weeks postpartum, one month postpartum, 3 months postpartum and 6 months postpartum. We collected the questionnaires at 3 days postpartum through a collection box and we collected the questionnaires at 2 weeks, one month, 3 months and 6 months postpartum by mail.

Women who were taking medication for psychological diseases and women who in the past had experienced death of a newborn infant or emergent hospitalization of a newborn infant were excluded. Women who were having difficulties in answering the questionnaire because of insufficient recovery mentally and physically and women who could not provide agreement and who could not answer the questionnaire by their own will were also excluded.

The contents of the questionnaires were as follows. The questionnaire given at 3 days postpartum had questions on background characteristics including age, parity, marital status, treatment for infertility and delivery method. The questionnaire given at one month postpartum had questions on abnormal results of medical examinations for the women and their infants. The questionnaire given at 6 months postpartum had questions on reoccurrence of menstruation until 6 months postpartum. The questionnaires given at all time points had questions 
on presence of an advisor, status of the mother's health, status of the infant's health, anxiety regarding family finances, relationship between the couple, sleeping hours and lactation method and also included the Japanese version of the Edinburgh Postnatal Depression Scale (EPDS). This version of EPDS was revised as a Japanese version for Japanese women, and a value of 9 points or more is assessed as a high score in Japan [15]. EPDS is a 10-item self-administered questionnaire that was originally developed to screen for postpartum depression [16].

Two scales were used in the study. First, we used psychological symptoms in a standard climacteric scale [17], which is a questionnaire for degrees of menopausal symptoms. Estrogen deficiency symptoms including psychological symptoms have been found in postpartum women as well as postmenopausal women. Thus, in Greene's climacteric scale, we asked about depressive symptoms (feeling tired or lacking in energy, loss of interest in most things, feeling unhappy or depressed, crying spells and irritability) and anxiety symptoms (heart beating quickly or strongly, feeling tense or nervous, difficulty in sleeping, excitable, pain attacks and difficulty in concentrating) with points from 0 (no symptom) to 3 (severe symptom). The points for depressive symptoms ranged from 0 to 15 and the points for anxiety symptoms ranged from 0 to 18 with a higher score indicating a stronger degree of a symptom. The reliability and validity of the scale were confirmed in a previous study [17].

We also used a questionnaire on involvement with infants that was developed in Japan in 2005 by Matsumura [18] since depressive symptoms and anxiety symptoms in postpartum women have relationships with involvement with newborn infants. The questionnaire included 7 questions on positive feelings and negative feelings for involvement with newborn infants. Two questions about wanting to hug newborn infants because they are so cute and about wanting to dearly protect newborn infants were given points from 1 (definitely no) to 5 (definitely yes). Five questions about finding it hard to take a break from the newborn infant and getting refreshed, not wanting to be near the newborn infant because the infant cries a lot, being tired from dealing with the newborn infant, putting up with a great deal around the newborn infant, and not wanting to change diapers and other messy things were given points from 1 (definitely yes) to 5 (definitely no). Thus, high total points mean positive feelings for involvement with newborn infants and low total points mean negative feelings for involvement with newborn infants. With respect to reliability for the scale, Cronbach's coefficient alpha was 0.733 . The validity of the scale was confirmed by confirmatory factor analysis and correlation between the subscales [18].

We analyzed data for postpartum women who responded to all of the 5 questionnaires during the 6-month postpartum period. Differences in characteristics between primiparous women and multiparous women during the 6-month postpartum period were analyzed by the t-test and the chi-square test. We used Fisher's exact test when the number of subjects was five or less. The scores for 
depressive symptoms and anxiety symptoms are shown as means \pm standard deviations. Differences in the scores for depressive symptoms and anxiety symptoms were analyzed by the paired t-test. Differences between factors in an increased group in which anxiety symptoms increased from one month postpartum to 3 months postpartum and an unchanged group in which anxiety symptoms did not increase during the same period were analyzed by using the chi-square test. Differences between factors in an increased group in which depressive symptoms increased from 3 months postpartum to 6 months postpartum and an unchanged group in which depressive symptoms did not increase during the same period were also analyzed by using the chi-square test. Correlations of depressive symptoms and anxiety symptoms with feelings for involvement with newborn infants during the 6-month postpartum period were analyzed by using Spearman's rank correlation coefficient test. Correlations of scores for depressive symptoms and anxiety symptoms with EPDS scores at all 5 time points during the 6-month postpartum period were also analyzed by using Spearman's rank correlation coefficient test. All statistical analyses were conducted with SPSS statistics ver. 24 (IBM Corp.).

This study was approved by the Research Ethics Committee of Tokushima University Hospital (approval number 2702). We first distributed an explanation sheet and a consent form to the subjects, and we received written informed consent for participation after explanation of the study including the aim of the study and methods used in the study, right of free participation, personal privacy protection and disadvantage by non-participation. We recruited participants who provided written informed consent.

\section{Results}

We distributed 229 questionnaires to two hospitals. Responses to all of the questionnaires at 3 days postpartum, 2 weeks postpartum, one month postpartum, 3 months postpartum and 6 months postpartum were obtained from $121(52.8 \%)$ of the 229 women. The primiparous women were 56 and multiparous women were 65 . The mean ages of the primiparous women were $30.8 \pm 4.9$ years and the multiparous women were $32.7 \pm 4.3$ years. There was a significant difference between the mean ages of the primiparous women and multiparous women at 3 days postpartum $(p=0.028)$. Also, the proportions of the women who had received treatment for infertility were significantly different in primiparous women and multiparous women $(\mathrm{p}=0.043)$ (Table 1).

There was a significant difference in status of the infant's health at 3 days postpartum between primiparous women and multiparous women $(p=0.007)$. There were also significant differences in the lactation method between primiparous women and multiparous women at 2 weeks postpartum $(p=0.001)$ and at one month postpartum $(\mathrm{p}=0.007)$. There were no significant differences in any of the items between primiparous women and multiparous women at 3 months and 6 months postpartum. The proportions of women with anxiety 
Table 1. Characteristics of the primiparous women and multiparous women.

\begin{tabular}{|c|c|c|c|c|c|c|}
\hline \multirow{3}{*}{$\begin{array}{c}\text { Postpartum } \\
\text { timepoint }\end{array}$} & \multirow{3}{*}{ Item } & & \multirow{3}{*}{ Total $\mathrm{N}=121$} & Primiparous women & Multiparaous women & \multirow{3}{*}{$P$ value } \\
\hline & & & & $\mathrm{N}=56$ & $\mathrm{~N}=65$ & \\
\hline & & & & Number (proportion) & Number (proportion) & \\
\hline \multirow{7}{*}{$\begin{array}{c}3 \text { days } \\
\text { postpartum }\end{array}$} & Age $(\text { years })^{a}$ & & $31.8 \pm 4.7$ & $30.8 \pm 4.9$ & $32.7 \pm 4.3$ & $0.028^{*}$ \\
\hline & \multirow[t]{2}{*}{ Marital status ${ }^{\mathrm{b}}$} & Married & $119(98.3)$ & $55(98.2)$ & $64(98.5)$ & \multirow[b]{2}{*}{0.915} \\
\hline & & Others & $2(1.7)$ & $1(1.8)$ & $1(1.5)$ & \\
\hline & \multirow[t]{2}{*}{ Delivery method ${ }^{\mathrm{b}}$} & Vaginal & $109(90.1)$ & $52(92.9)$ & $57(87.7)$ & \multirow{2}{*}{0.343} \\
\hline & & Cesarean section & $12(9.9)$ & $4(7.1)$ & $8(12.3)$ & \\
\hline & Treatment for infertility ${ }^{\mathrm{b}}$ & No & $98(81.0)$ & $41(73.2)$ & $57(87.7)$ & \multirow{2}{*}{$0.043^{*}$} \\
\hline & & Yes & $23(19.0)$ & $15(26.8)$ & $8(12.3)$ & \\
\hline \multirow{4}{*}{$\begin{array}{l}\text { One month } \\
\text { postpartum }\end{array}$} & Abnormal results of medical & No & $116(95.9)$ & $53(94.6)$ & $63(96.9)$ & \multirow{2}{*}{0.530} \\
\hline & examination in mothers & Yes & $5(4.1)$ & $3(5.4)$ & $2(3.1)$ & \\
\hline & \multirow{2}{*}{$\begin{array}{l}\text { Abnormal results of medical } \\
\text { examination in infants }{ }^{\mathrm{b}}\end{array}$} & No & $118(97.5)$ & $54(96.4)$ & $64(98.5)$ & \multirow{2}{*}{0.473} \\
\hline & & Yes & $3(2.5)$ & $2(3.6)$ & $1(1.5)$ & \\
\hline \multirow{2}{*}{$\begin{array}{l}6 \text { months } \\
\text { postpartum }\end{array}$} & Occurrence of menstruation & Yes & $47(38.8)$ & $26(46.4)$ & $21(32.3)$ & \multirow{2}{*}{0.112} \\
\hline & until six months postpartum ${ }^{\mathrm{b}}$ & No & $74(61.2)$ & $30(53.6)$ & $44(67.7)$ & \\
\hline
\end{tabular}

${ }^{a}$ Age is shown as mean \pm standard deviation are shown in age. Statistical analysis was used by t-test. ${ }^{b}$ Statistical analysis was used by chi-square test $(5$ or less are Fisher's test). ${ }^{*} \mathrm{p}<0.05$.

about family finances ranged from $37.5 \%$ to $50.0 \%$ in primiparous women and from $32.3 \%$ to $41.5 \%$ in multiparous women during the 6 -month postpartum period (Table 2).

We compared scores for depressive symptoms and anxiety symptoms with EPDS scores in order to confirm whether scores for depressive symptoms and anxiety symptoms are appropriate for evaluation of postpartum psychological symptoms. The scores for depressive symptoms and anxiety symptoms showed strong positive correlations with EPDS scores $(\rho=0.566$ and $p<0.001$ at 3 days postpartum, $\rho=0.755$ and $\mathrm{p}<0.001$ at 2 weeks postpartum, $\rho=0.709$ and $\mathrm{p}<$ 0.001 at 1 month postpartum, $\rho=0.598$ and $\mathrm{p}<0.001$ at 3 months postpartum, and $\rho=0.602$ and $\mathrm{p}<0.001$ at 6 months postpartum).

Transition of depressive symptoms and anxiety symptoms according to parity (Figure 1(a), Figure 1(b))

Regarding the transition of depressive symptoms and anxiety symptoms according to parity during the 6-month postpartum period, the score for depression at 3 days postpartum in primiparous women was significantly higher than that in multiparous women $(\mathrm{p}=0.025)$. However, there were no significant differences in the scores for depressive symptoms and anxiety symptoms between primiparous women and multiparous women at the other four time points during the postpartum period.

Also, scores for both depressive symptoms and anxiety symptoms showed peaks at 2 weeks postpartum and decreased thereafter. The scores for depressive 


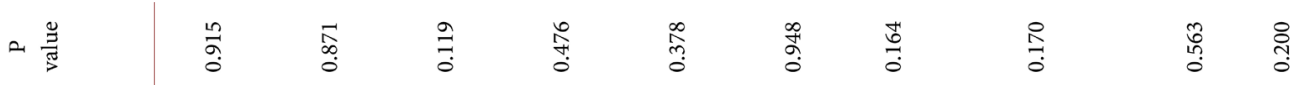

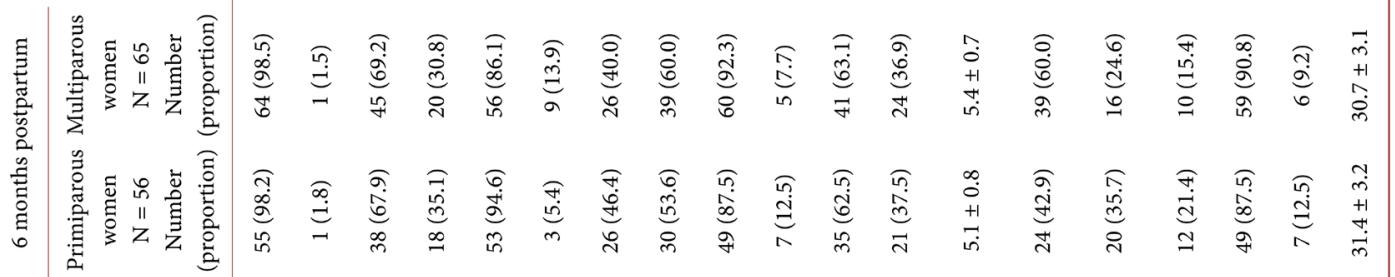

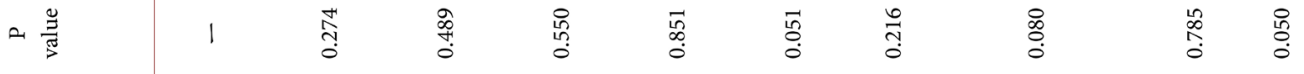

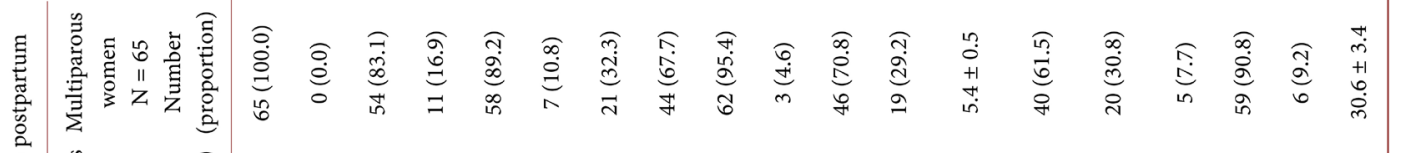

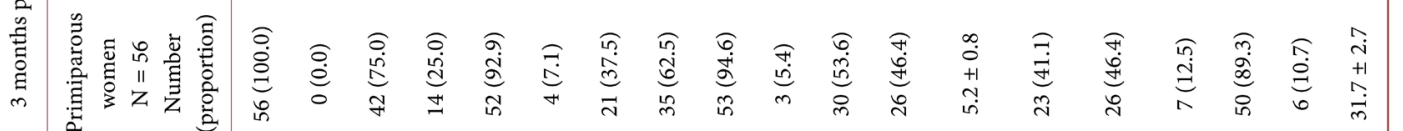

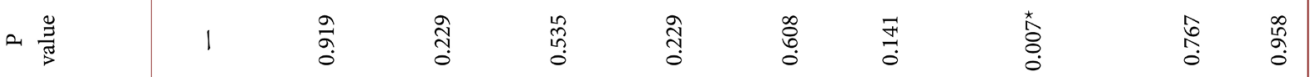

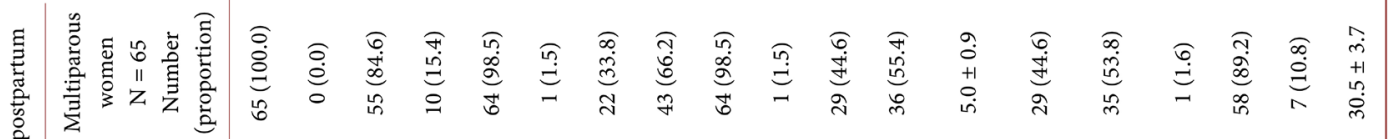

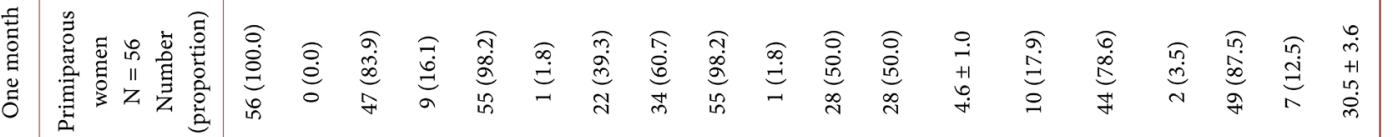

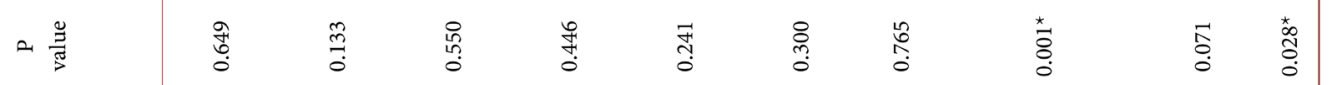

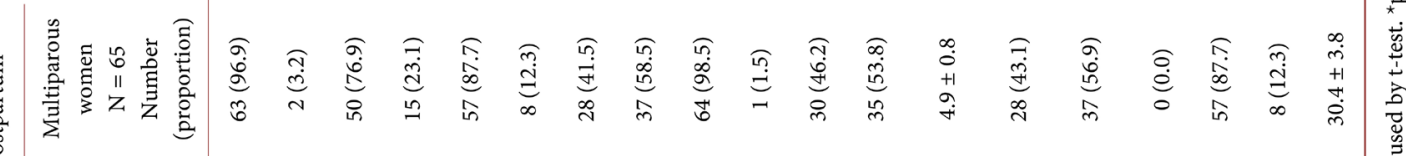

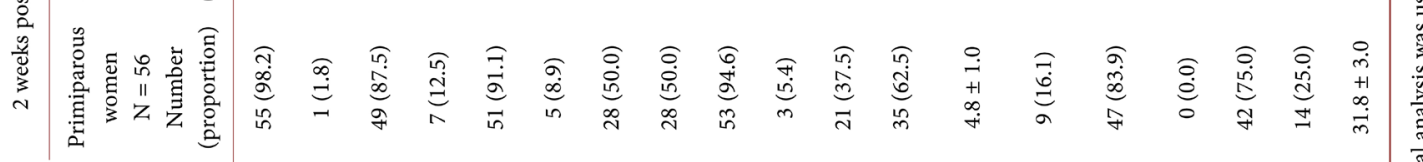

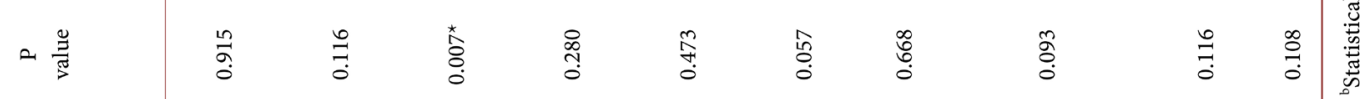

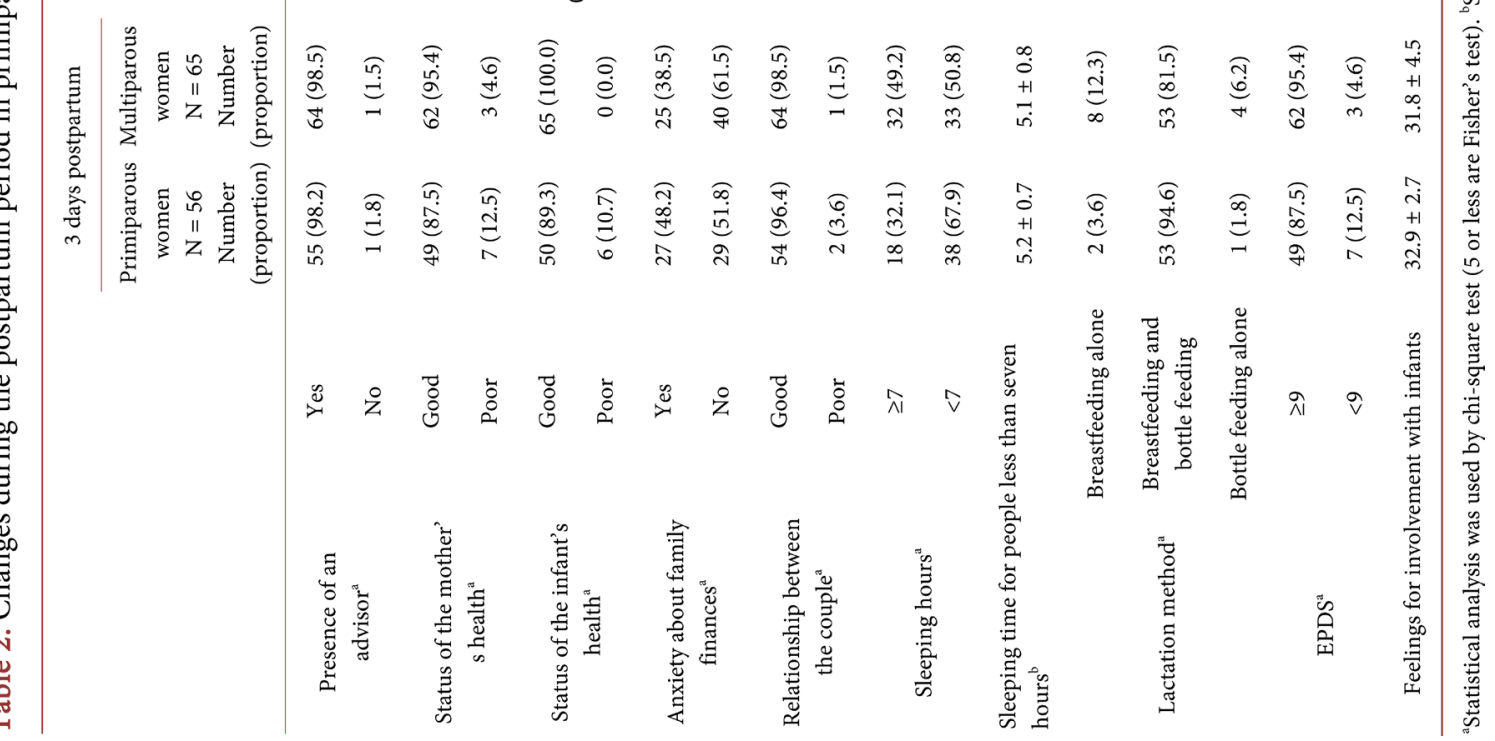



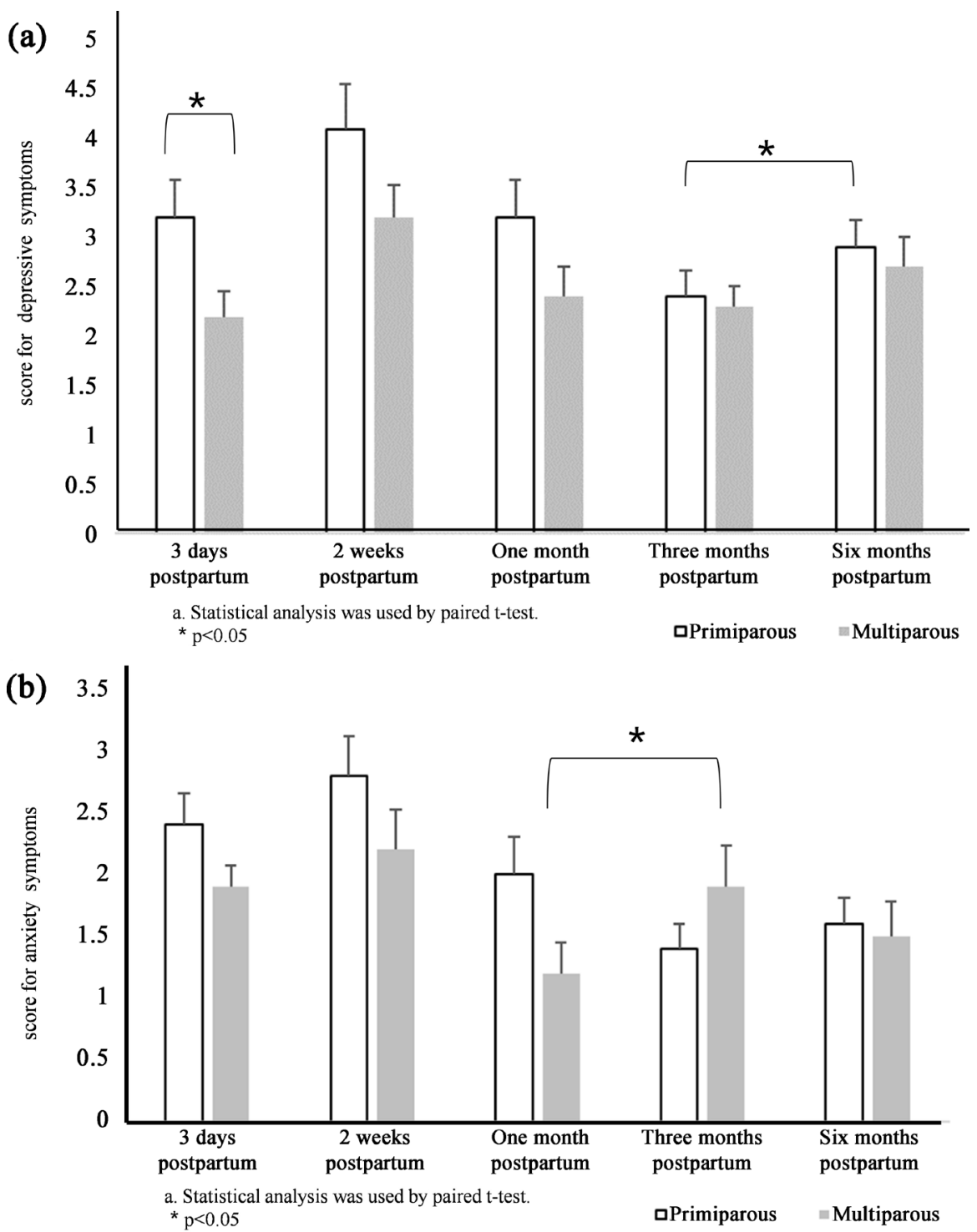

Open column: primiparous women; Closed column: multiparous women; Statistical analysis was used by paired t-test. ${ }^{*} \mathrm{p}<0.05$.

Figure 1. (a) Scores for depressive symptoms during the 6-month postpartum period ${ }^{\text {a }}$; (b) Scores for anxiety symptoms during the 6-month postpartum period ${ }^{\mathrm{a}}$.

symptoms were decreased at 3 months postpartum but were increased at 6 months postpartum in both primiparous women and multiparous women, and the increase in the score for primiparous women was significant $(p=0.029)$. The score for anxiety symptoms in primiparous women was decreased at 3 months postpartum, but the score for anxiety symptoms in multiparous women was increased significantly at 3 months postpartum $(p=0.009)$.

Differences in background characteristics between the group in which psychological symptoms increased and the group in which psychological symptoms did not increase (Table 3)

In primiparous women, we compared various factors including presence of an advisor, mother's health, infant's health, anxiety about family finances, relationship 
Table 3. Differences in factors between the increased group and no change group in depressive symptoms at 3 months and 6 months postpartum in primiparous women and anxiety symptoms at 1 month and 3 months postpartum in multiparous women ${ }^{\mathrm{a}}$.

\begin{tabular}{|c|c|c|c|c|c|c|c|}
\hline & & \multicolumn{2}{|c|}{$\begin{array}{l}\text { Depression at six months in } \\
\text { primiparous women }\end{array}$} & \multirow[b]{2}{*}{$P$ value } & \multicolumn{2}{|c|}{$\begin{array}{l}\text { Anxiety at three months in } \\
\text { multiparous women }\end{array}$} & \multirow[b]{2}{*}{$P$ value } \\
\hline & & $\begin{array}{l}\text { Increased group } \\
\qquad(\mathrm{n}=30) \\
\text { Number } \\
\text { (proportion) }\end{array}$ & $\begin{array}{l}\text { No change group } \\
\qquad(\mathrm{n}=26) \\
\text { Number } \\
\text { (proportion) }\end{array}$ & & $\begin{array}{l}\text { Increased group } \\
\qquad(\mathrm{n}=24) \\
\text { Number } \\
\text { (proportion) }\end{array}$ & $\begin{array}{l}\text { No change group } \\
\quad(\mathrm{n}=41) \\
\text { Number } \\
\text { (proportion) }\end{array}$ & \\
\hline \multirow{3}{*}{$\begin{array}{l}\text { Presence of an } \\
\text { advisor }\end{array}$} & Yes & $29(96.7)$ & $25(96.2)$ & \multirow{3}{*}{0.286} & $24(100.0)$ & $41(0.0)$ & \multirow{3}{*}{-} \\
\hline & No & $0(0.0)$ & $1(3.8)$ & & $0(0.0)$ & $0(0.0)$ & \\
\hline & Unknown & $1(3.3)$ & $0(0.0)$ & & $0(0.0)$ & $0(0.0)$ & \\
\hline \multirow{2}{*}{$\begin{array}{l}\text { Status of the } \\
\text { mother's health }\end{array}$} & Good & $19(63.3)$ & $19(73.1)$ & \multirow{2}{*}{0.436} & $21(87.5)$ & $33(80.5)$ & \multirow{2}{*}{0.467} \\
\hline & Poor & $11(36.7)$ & $7(26.9)$ & & $3(12.5)$ & $8(19.5)$ & \\
\hline \multirow{3}{*}{$\begin{array}{l}\text { Status of the } \\
\text { newborn infant's } \\
\text { health }\end{array}$} & Good & $28(93.4)$ & $24(92.3)$ & & $21(87.5)$ & $37(90.2)$ & \multirow{3}{*}{0.731} \\
\hline & Poor & $1(3.3)$ & $2(7.7)$ & 0.489 & $3(12.5)$ & $4(9.8)$ & \\
\hline & Unknown & $1(3.3)$ & $0(0.0)$ & & $0(0.0)$ & $0(0.0)$ & \\
\hline \multirow{3}{*}{$\begin{array}{l}\text { Anxiety about family } \\
\text { finances }\end{array}$} & Yes & $13(43.4)$ & $13(50.0)$ & & $6(25.0)$ & $15(36.6)$ & \multirow{3}{*}{0.303} \\
\hline & No & $16(53.3)$ & $13(50.0)$ & 0.701 & $18(75.0)$ & $25(61.0)$ & \\
\hline & Unknown & $1(3.3)$ & $0(0.0)$ & & $0(0.0)$ & $1(2.4)$ & \\
\hline \multirow{3}{*}{$\begin{array}{c}\text { Relationship } \\
\text { between the couple }\end{array}$} & Good & $26(86.8)$ & $23(88.5)$ & & $23(95.8)$ & $39(95.2)$ & \multirow{3}{*}{0.711} \\
\hline & Poor & $2(6.6)$ & $2(7.7)$ & 0.906 & $1(4.2)$ & $1(2.4)$ & \\
\hline & Unknown & $2(6.6)$ & $1(3.8)$ & & $0(0.0)$ & $1(2.4)$ & \\
\hline \multirow[t]{3}{*}{ Sleeping hours } & $\geq 7$ & $14(46.7)$ & $20(76.9)$ & & $15(62.5)$ & $31(75.6)$ & \multirow{3}{*}{0.262} \\
\hline & $<7$ & $15(50.0)$ & $6(23.1)$ & ${ }^{\star} 0.029$ & $9(37.5)$ & $10(24.4)$ & \\
\hline & Unknown & $1(3.3)$ & $0(0.0)$ & & $0(0.0)$ & $0(0.0)$ & \\
\hline \multirow[t]{4}{*}{ Lactation method } & Breastfeeding alone & $14(46.7)$ & $10(38.5)$ & \multirow{4}{*}{0.518} & $15(62.5)$ & $25(61.0)$ & \multirow{4}{*}{0.764} \\
\hline & $\begin{array}{l}\text { Breastfeeding and bottle } \\
\text { feeding }\end{array}$ & $8(26.7)$ & $11(42.3)$ & & $8(33.3)$ & $12(29.3)$ & \\
\hline & Bottle feeding alone & $7(23.3)$ & $5(19.2)$ & & $1(4.2)$ & $4(9.7)$ & \\
\hline & Unknown & $1(3.3)$ & $0(0.0)$ & & $0(0.0)$ & $0(0.0)$ & \\
\hline \multirow[t]{2}{*}{ EPDS } & $\geq 9$ & $5(16.7)$ & $3(11.5)$ & \multirow{2}{*}{0.584} & $4(16.7)$ & $2(4.8)$ & \multirow{2}{*}{0.113} \\
\hline & $<9$ & $25(83.3)$ & $23(88.5)$ & & $20(83.3)$ & $39(95.2)$ & \\
\hline
\end{tabular}

a Statistical analysis was used by chi-square test. ${ }^{*} \mathrm{p}<0.05$. EPDS: Edinburgh postnatal depression scale.

between the couple, sleeping hours, lactation method and EPDS between a group in which depressive symptoms increased from 3 months postpartum to 6 months postpartum and a group in which depressive symptoms did not increase during the same period. There was a significant difference between the two groups in sleeping hours $(\mathrm{p}=0.029)$, and the proportion of postpartum women whose sleeping time was less than 7 hours was high. Also, in multiparous women, we compared the factors between a group in which anxiety symptoms in- 
creased from 1 month postpartum to 3 months postpartum and a group in which anxiety symptoms did not increase during the same period. There was no significant difference between the two groups in any of the factors.

Correlations of depressive symptoms and anxiety symptoms with feelings for involvement with newborn infants (Table 4, Table 5)

Depressive symptoms The numbers of significant and negative correlations between depression score and scores of feelings for involvement with newborn infants in multiparous women were larger than those in primiparous women at 3 days postpartum and at one month postpartum. At one month postpartum, many significant and negative correlations were found in both primiparous women and multiparous women. At 6 months postpartum, there were more significant and negative correlations between depression score and scores of feelings for involvement with newborn infants in primiparous women. In primiparous women, depression score was significantly and negatively correlated with the item of having to put up with a great deal around newborn infants at all time points during the 6-month postpartum period. Depression score was associated with negative feelings for involvement with newborn infants. In multiparous women, depression score was significantly and negatively correlated with the item of having to put up with a great deal around newborn infants at all time points except for 6 months postpartum.

Anxiety symptoms The numbers of significant and negative correlations between anxiety score and scores of feelings for involvement with newborn infants in multiparous women were larger than those in primiparous women at 3 days postpartum, 2 weeks postpartum, one month postpartum and 3 months postpartum. In multiparous women, anxiety score was significantly and negatively associated with the item of not wanting to be near the newborn infant because the infant cries a lot at 2 weeks postpartum, one month postpartum, 3 months postpartum and 6 months postpartum. In multiparous women, anxiety score was significantly and negatively associated with the item of having to put up with a great deal around newborn infants at 3 days postpartum, 2 weeks postpartum, one month postpartum and 3 months postpartum. Thus, anxiety score was associated with negative feelings for involvement with newborn infants during the 6-month postpartum period.

\section{Discussion}

The score for depressive symptoms in primiparous women was significantly higher than that in multiparous women at 3 days postpartum. There have been few studies in which the difference in depressive symptoms according to parity was examined at 3 days postpartum. It has been reported that most cases of postpartum depression occurred within one week after delivery [19]. However, many longitudinal studies on psychological status in postpartum women were conducted after 1 week postpartum [7] [20] [21]. To prevent progression to severe depressive symptoms and anxiety symptoms, it is necessary to clarify the 


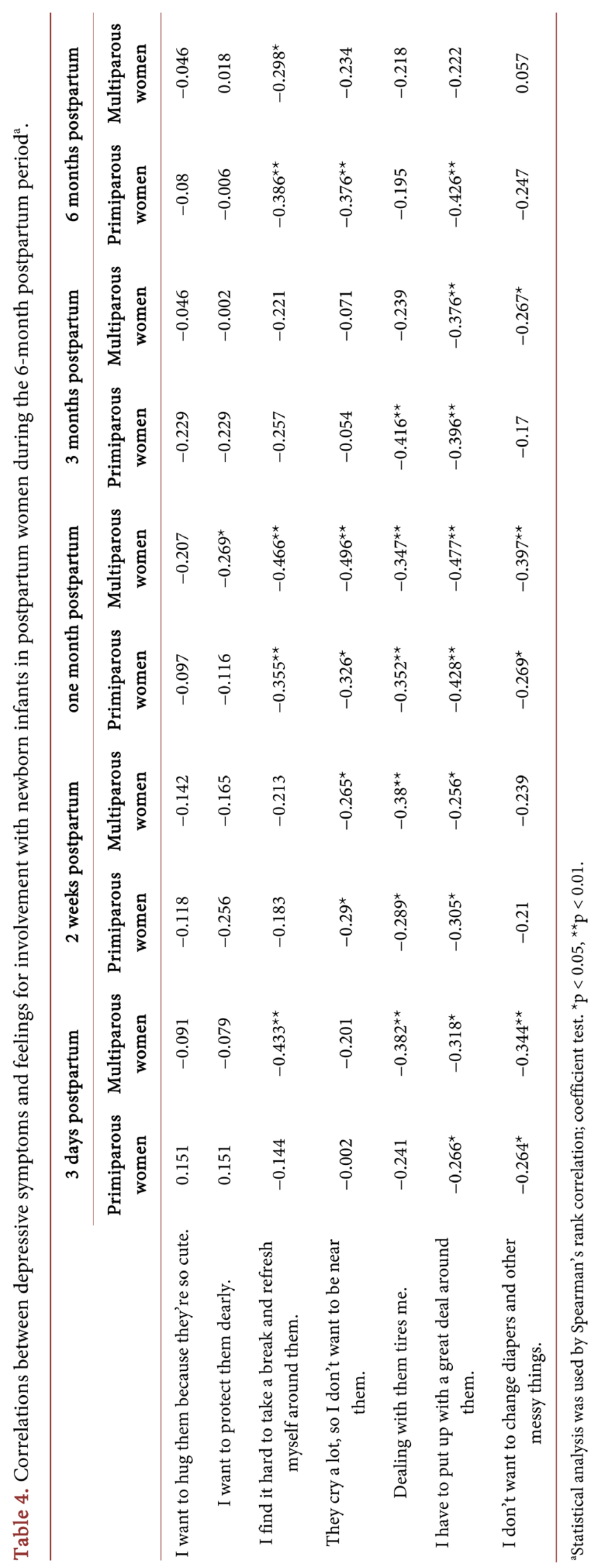




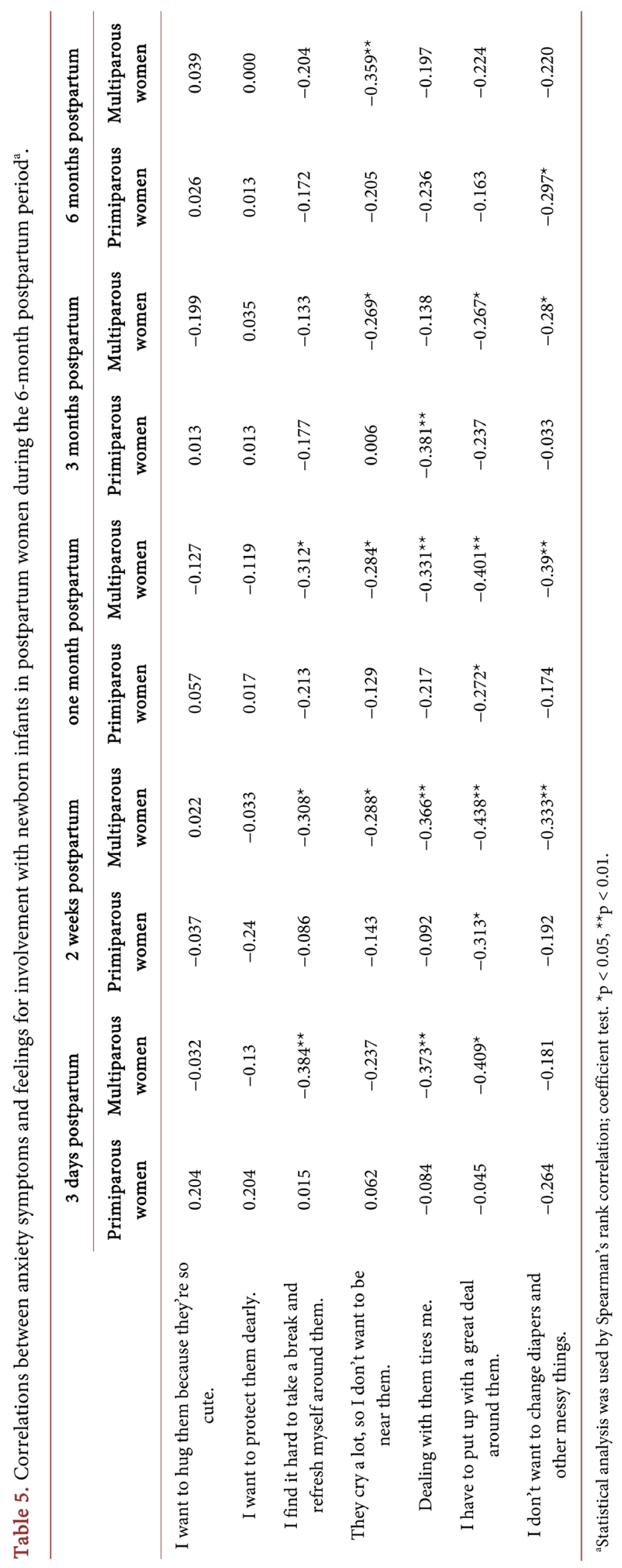


actual condition of depression in postpartum women and depression-related factors by starting a study from the early stage of postpartum.

We found that the occurrence of depressive symptoms and the occurrence of anxiety symptoms showed peaks at 2 weeks postpartum in both primiparous women and multiparous women. It has been reported that the occurrence of depressive symptoms in women whose EPDS score was 9 or more showed a peak at 2 weeks postpartum in primiparous women but not in multiparous women and that the occurrence of depressive symptoms in multiparous women gradually decreased from a few days to 3 months postpartum [5]. Primiparity has been shown to be a risk factor for postpartum depression [12] [13]. Therefore, care for primiparous women who have experienced delivery and child rearing for the first time has been focused on. However, psychological care is needed for multiparous women as well as primiparous women regardless of the experience of delivery and child-rearing since depression symptoms and anxiety symptoms showed peaks at 2 weeks postpartum in both multiparous women and primiparous women in this study.

In the present study, we found that there was recurrence of depressive symptoms at 3 months postpartum and 6 months postpartum in primiparous women and that there was recurrence of anxiety symptoms at one month postpartum and 3 months postpartum in multiparous women. There has been no report on the recurrence of depressive symptoms and anxiety symptoms during the postpartum period. We also showed that sleeping hours might be a factor related to the recurrence of depressive symptoms in primiparous women. Since insufficient sleeping hours for a long time during puerperium affects the psychological status of postpartum women, it is necessary to confirm that postpartum women have living conditions in which appropriate sleeping hours can be secured and to provide support for improvement of living conditions in women with insufficient sleeping hours. The reason for recurrence of anxiety symptoms in multiparous women was not clarified. Support for multiparous women is also needed because they are raising their older child or children as well as their newborn infant. Based on the results in the present study, sustained care by midwives is needed not only for women during pregnancy, delivery and puerperium but also for child-rearing women as health care.

There was no occurrence of menstruation in $53.6 \%$ of the primiparous women and $67.7 \%$ of the multiparous women up to six months postpartum. Given that there was a high correlation between Greene's scale and EPDS scale, estrogen deficiency might be a reason for the occurrence of depressive symptoms and anxiety symptoms during the postpartum period.

Examination of the relationships of depressive symptoms and anxiety symptoms with feelings for involvement with newborn infants showed that depression symptoms were associated with negative feelings for involvement with newborn infants in primiparous women and that both depressive symptoms and anxiety symptoms were associated with negative feelings for involvement with 
newborn infants in multiparous women. Primiparous women want to be involved with their newborn infant immediately after delivery and they have some conflict between interest in and anxiety about child rearing. With advance of the postpartum period, primiparous women experience an increasing number of situations in which they cannot cope well with their newborn infants. Therefore, the score for depressive symptoms might be high in the early postpartum period. Support for successful experiences as a mother after delivery may be necessary for primiparous women in order to prevent the occurrence of depressive symptoms. On the other hand, we showed that anxiety was associated with negative feelings in multiparous women of not wanting to be near their newborn infant because the infant cries a lot and having to put up with a great deal around their newborn infant. It has been reported that the psychological status of postpartum women has effects on attachment to children [22] and the mother-child relationship [23]. Negative feelings for involvement with newborn infants in postpartum women who are in an unstable psychological state may lead to abuse against newborn infants and suicide. It has been reported that maternal attachment in multiparous women is stable since multiparous women have positive maternal attachment at an early stage of puerperium [24]. Even in multiparous postpartum women who have experienced child rearing, we found that depressive symptoms and anxiety symptoms were associated with negative feelings for involvement with newborn infants during a 6-month postpartum period. Multiparous women have the first experience of raising more than one child at the same time. This may be a reason for anxiety emotion. Given that multiparous women have negative maternal attachment regarding involvement with the older child and have anxiety about growth and development of the older child, it is important for midwifery to understand the anxiety and to provide support for child rearing from a multiparous women's point of view.

This study has several limitations. Since we recruited subjects in a limited area and the number of subjects was small, generalization of the results obtained in the present study is limited. Differences in problems for child rearing between primiparous women and multiparous women need to be clarified.

\section{Conclusion}

Changes in depressive symptoms and anxiety symptoms were different in primiparous women and multiparous women during a 6-month postpartum period. In addition, depressive symptoms and anxiety symptoms were associated with negative feelings for involvement with newborn infants and with sleeping time in postpartum women.

\section{Acknowledgements}

The authors are grateful to doctors, midwives and medical assistants in Sanuki Municipal Hospital and Tsurugi-Handa Hospital for supporting this research. We also thank the women who participated in this study. 


\section{Conflicts of Interest}

The authors declare no conflicts of interest regarding the publication of this paper.

\section{References}

[1] Miura, R., Tani, Y., Fujiwara, T., Kawachi, I., Hanazato, M. and Kim, Y. (2019) Multilevel Analysis of the Impact of Neighborhood Environment on Postpartum Depressive Symptoms. Journal of Affective Disorders, 263, 593-597. https://doi.org/10.1016/j.jad.2019.11.033

[2] Maeda, Y., Ogawa, K., Morisaki, N., Tachibana, Y., Horikawa, R. and Sago, H. (2019) Association between Perinatal Anemia and Postpartum Depression: A Prospective Cohort Study of Japanese Women. International Journal of Gynecology and Obstetrics, 148, 48-52. https://doi.org/10.1002/ijgo.12982

[3] Goodman, J.H., Watson, G.R. and Stubbs, B. (2016) Anxiety Disorders in Postpartum Women: A Systematic Review and Meta-Analysis. Journal of Affective Disorders, 203, 292-331. https://doi.org/10.1016/j.jad.2016.05.033

[4] Hantsoo, L. and Epperson, N. (2017) Anxiety Disorders among Women: A Female Lifespan Approach. Focus: The Journal of Lifelong Learning in Psychiatry, 15, 162-172. https://doi.org/10.1176/appi.focus.20160042

[5] Takehara, K., Tachibana, Y., Yoshida, K. and Mori, R. (2018) Prevalence Trends of Pre- and Postnatal Depression in Japanese Women: A Population-Based Longitudinal Study. Journal of Affective Disorders, 225, 389-394.

https://doi.org/10.1016/j.jad.2017.08.008

[6] Iwata, H., Mori, E., Sakajo, A. and Aoki, K. (2016) Prevalence of Postpartum Depressive Symptoms during the First 6 Months Postpartum: Association with Maternal Age and Parity. Journal of Affective Disorders, 203, 227-232. https://doi.org/10.1016/j.jad.2016.06.002

[7] Shimizu, A., Nishiumi, H., Okumura, Y. and Watanabe, K. (2015) Depressive Symptoms and Changes in Physiological and Social Factors 1 Week to 4 Months Postpartum in Japan. Journal of Affective Disorders, 179, 175-182. https://doi.org/10.1016/j.jad.2015.03.036

[8] Moses-Kolko, E.L., Berga, S.L., Kalro, B., Sit, D.K. and Wisner, K.L. (2009) Transdermal Estradiol for Postpartum Depression: A Promising Treatment Option. Clinical Obstetrics and Gynecology, 52, 516-529. https://doi.org/10.1097/GRF.0b013e3181b5a395

[9] Skalkidou, A., Hellgren, C., Comasco, E., Sylvén, S. and Poromaa, S.I. (2012) Biological Aspects of Postpartum Depression. Women's Health, 8, 659-672. https://doi.org/10.2217/whe.12.55

[10] Yim, I.S., Tanner Stapleton, L.R., Guardino, C.M., Hahn-Holbrook, J. and Dunkel-Schetter, C. (2015) Biological and Psychosocial Predictors of Postpartum Depression: Systematic Review and Call for Integration. Annual Review of Clinical Psychology, 11, 99-137. https://doi.org/10.1146/annurev-clinpsy-101414-020426

[11] Campbell, O.M. and Gray R.H. (1993) Characteristics and Determinants of Postpartum Ovarian Function in Women in the United States. American Journal of $O b$ stetrics and Gynecology, 169, 55-60. https://doi.org/10.1016/0002-9378(93)90131-2

[12] Tachibana, Y., Koizumi, T., Takehara, K., Kakee, N., Tsujii, H., Mori, R., Inoue, E., Ota, E., Yoshida, K., Kasai, K., Okuyama, M. and Kubo, T. (2015) Antenatal Risk Factors Postpartum Depression at 20 Weeks Gestation in a Japanese Sample: Psy- 
chosocial Perspectives from a Cohort Study in Tokyo. PLoS ONE, 10, e0142410. https://doi.org/10.1371/journal.pone.0142410

[13] Smorti, M., Ponti, L. and Pancetti, F. (2019) A Comprehensive Analysis of Post-Partum Depression Risk Factors: Role of Socio-Demographic, Individual, Relational, and Delivery Characteristics. Frontiers in Public Health, 7, 295. https://doi.org/10.3389/fpubh.2019.00295

[14] Nagata, M., Nagai, Y., Sobajima, H., Ando, T. and Honjo, S. (2003) Depression in the Mother and Maternal Attachment-Results from a Follow-Up Study at 1 Year Postpartum. Psychopathology, 36, 142-151. https://doi.org/10.1159/000071259

[15] Okano, T., Murata, M., Masuji, F., Tamaki, R., Nomura, J., Miyaoka, H. and Kitamura, T. (1996) Validation and Reliability of Japanese Version of EPDS. Archives of Psychiatric Diagnostics and Clinical Evaluation, 7, 525-533.

[16] Cox, J.L., Holden, J.M. and Sagovsky, R. (1987) Detection of Postnatal Depression: Development of the 10-Item Edinburgh Postnatal Depression Scale. The British Journal of Psychiatry, 150, 782-786. https://doi.org/10.1192/bjp.150.6.782

[17] Greene, J.G. (1998) Constructing a Standard Climacteric Scale. Maturitas, 29, 25-31. https://doi.org/10.1016/S0378-5122(98)00025-5

[18] Matsumura, K. (2005) Consideration of “Motherhood Awareness”. Bungeisya, Tokyo.

[19] Yamashita, H., Yoshida, K., Nakano, H. and Tashiro, N. (2000) Postnatal Depression in Japanese Women: Detecting the Early Onset of Postpartum Depression by Closely Monitoring the Postpartum Mood. Journal of Affective Disorders, 58 145-154. https://doi.org/10.1016/S0165-0327(99)00108-1

[20] Taylor, J. and Johnson, M. (2013) The Role of Anxiety and Other Factors in Predicting Postnatal Fatigue: From Birth to 6 Months. Midwifery, 29, 526-534. https://doi.org/10.1016/j.midw.2012.04.011

[21] Chen, H.H., Hwang, F.M., Lin, L.J., Han, K.C., Lin, C.L. and Chien, Ki.Y. (2016) Depression and Social Support Trajectories during 1 Year Postpartum among Marriage-Based Immigrant Mothers in Taiwan. Archives of Psychiatric Nursing, 30, 350-353. https://doi.org/10.1016/j.apnu.2015.12.008

[22] Aceti, F., Baglioni, V., Carluccio, G.M., Colosimo, D., Giacchetti, N., Marini, I., Meuti, V., Motta, P., Zaccagni, M. and Biondi, M. (2012) Perinatal and Postpartum Depression: From Attachment to Personality. A Pilot Study. Journal of Psychopathology, 18, 328-334.

[23] Righetti-Veltema, M., Bousquet, A. and Manzono, J. (2003) Impact of Postpartum Depressive Symptoms on Mother and Her 18-Month-Old Infant. European Child and Adolescent Psychiatry, 12, 75-83. https://doi.org/10.1007/s00787-003-0311-9

[24] Fukuzawa, Y. and Yamakawa, Y. (2006) Maternal Attachment and Mental State of Mothers at One Month Postpartum. Kawasaki Medical Welfare Journal, 16, 81-89. 